\title{
Application of Sakhaptinsk Zeolite for Improving the Quality of Ground Water
}

\author{
Olga Nazarenko ${ }^{1, *}$, Raisa Zarubina ${ }^{2}$ \\ ${ }^{1}$ Institute of Non-Destructive Testing, Tomsk Polytechnic University, Tomsk, 634050, Russia \\ ${ }^{2}$ Institute of Natural Resources, Tomsk Polytechnic University, Tomsk, 634050, Russia \\ *Corresponding Author: Second obnaz@mail.com
}

Copyright $(2013$ Horizon Research Publishing All rights reserved.

\begin{abstract}
The physico-chemical properties of natural zeolite from the Sakhaptinsk deposit (Krasnoyarsk Territory, Russia) were studied. The ability to use this zeolite for improving the quality of potable water was shown. The water treatment was carried out under dynamic conditions. Pre-treatment of the zeolite by the $\mathrm{NaCl}$ solution before experiment was carried out. The treated ground water (Kozhevnikovsky district, Tomsk region, Russia) was characterized by high concentration of iron and manganese. Obtained results indicate that natural zeolite of Sakhaptinsk deposit can be used for removal of iron and manganese and is suitable for drinking and household purposes.
\end{abstract}

Keywords Zeolite, Clinoptololite, Iron, Manganese, Water Treatment, Ion-Exchange

\section{Introduction}

Surface waters of the Tomsk region are heavily polluted by wastewater of industrial and agricultural enterprises, oil and gas companies. Therefore, the populations of Tomsk region (West Siberia) use ground water as the source of drinking and household water supplies. Ground water of the Tomsk region is characterized by high content of iron up to $20 \mathrm{mg} / \mathrm{L}$, manganese up to $15 \mathrm{mg} / \mathrm{L}$, ammonium up to 5 $\mathrm{mg} / \mathrm{L}$, silicon up to $20 \mathrm{mg} / \mathrm{L}$ [1-3]. The quality of groundwater in under natural conditions does not meet the limits set under the sanitary and epidemiological rules and regulations of Russian Federation SanPiN 2.1.4.1074-01 "Drinking Water. Hygienic Requirements for Quality of Water in the Centralized Drinking Water Supply Systems. Quality Control". The maximum allowable concentration (MAC) in drinking water pursuant to regulations SanPiN 2.1.4.1074-01 for iron is $0.3 \mathrm{mg} / \mathrm{L}$ and for manganese is $0.1 \mathrm{mg} / \mathrm{L}$.

Iron in ground water is contained as a divalent ion $\mathrm{Fe}^{2+}$. After lifting the water to the surface and oxidation by atmospheric oxygen, iron $\mathrm{Fe}^{2+}$ transforms to the trivalent form $\mathrm{Fe}^{3+}$. Water use of such a composition requires special water treatment, including, as a rule, aeration to convert ferrous ion $\mathrm{Fe}^{2+}$ in ferric ion $\mathrm{Fe}^{3+}$, sedimentation and filtration.

In the small settlements of the Tomsk region the technology of water treatment is usually primitive and involves only the stage of sedimentation. The use of groundwater for drinking purposes without purification poses a threat to human health, causing various diseases, so the providing the population of Tomsk region with quality drinking water is a serious problem.

Several treatment technologies, such as ozonation [2-7], electric discharge treatment $[2,8,9]$, have been developed for ground water purification. However, high power consumption and expenses are required for operation and maintenance of the equipment. Wide spread, cheapness and high sorption properties of natural minerals, including zeolites, allow considering them as perspective sorbents for different impurities removal.

Natural zeolites are crystalline hydrated aluminosilicate minerals with a framework structure containing pores. The general formula of a zeolite is follows:

$$
\mathrm{M}_{m / n}\left[\left(\mathrm{AlO}_{2}\right)_{x} \cdot\left(\mathrm{SiO}_{2}\right)_{y}\right] \cdot z \mathrm{H}_{2} \mathrm{O},
$$

where $\mathrm{M}$ is monovalent $\left(\mathrm{Na}^{+}, \mathrm{K}^{+}, \mathrm{Li}^{+}\right)$or divalent $\left(\mathrm{Ca}^{2+}\right.$, $\left.\mathrm{Mg}^{2+}, \mathrm{Ba}^{2+}, \mathrm{Sr}^{2+}\right)$ exchangeable cations, $m$ is number of cations $\mathrm{M}, n$ is cation charge, ratio $y / x=1-6$ depending on the structure, $z$ is number of water molecules $[10,11]$. Natural zeolites are characterized with high cation-exchange ability and molecular sieve properties; they are low-cost materials, easily available in large quantities. That is why zeolites are widely used for drinking water and wastewater treatment [12-15].

Natural zeolites or modified zeolites can be used as a adsorption material for removal of iron and manganese from water [16-18]. Activated natural zeolite from deposit in the East Slovakia Region was used to iron and manganese removal to the permissible values [16]. It was shown that activated zeolite is comparable to the imported filtration material Birm. Results were obtained in [16] using a natural zeolite which indicate that at the initial Fe concentration of $0.5 \mathrm{mg} / \mathrm{dm}^{3}$ the removal percentage of this ion was 92 ; and 
for initial $\mathrm{Mn}$ concentration of $3.00 \mathrm{mg} / \mathrm{dm}^{3}$ the removal percentage was 72.3 .

In Russia, the zeolitic rocks are widespread. In the southern area of Krasnoyarsk region there are deposits: Pashensk, Sakhaptinsk, Syrsk, and Pashkino. The mineral composition of deposits is clay-feldspar-quartz-zeolite. Zeolite minerals are represented by clinoptilolite and heulandite. The content of the zeolite ranges from 10 to $60 \%$ or more.

Sorption properties of the Sakhaptinsk zeolite were studied insufficiently, in contrast to other deposits of zeolites. The processes of extracting oil from water contaminated by oil and gasoline $[19,20]$ using Sakhaptinsk zeolite were studied. Some properties of the Sakhaptinsk zeolite were studied in [21] and the prospects of using the zeolite rock in mixed gypsum-zeolite, zeolite-magnesium, and lime-zeolite binders were determined.

Despite the large number of different experimental and theoretical studies of wastewater and water treatment based on natural zeolites, each type of zeolite raw material possesses unique properties; therefore each zeolite rock requires a separate study.

The aim of the present work is to study the possibility of using the Sakhaptinsk zeolite (Krasnoyarsk region, Russia) for improving the quality of water by removal of iron and manganese ions under dynamic conditions.

\section{Materials and Methods}

\subsection{Zeolite Sample}

Zeolite rock from the Sakhaptinsk deposit (Krasnoyarsk The chemical composition of the Sakhaptinsk rock sample was determined by classical chemical analysis (Table 1).

Table 1. Chemical composition of the Sakhaptinsk zeolite

\begin{tabular}{|c|c|}
\hline Component & Value (\%) \\
\hline $\mathrm{SiO}_{2}$ & 66.01 \\
\hline $\mathrm{Fe}_{2} \mathrm{O}_{3}$ & 2.36 \\
\hline $\mathrm{Al}_{2} \mathrm{O}_{3}$ & 12.51 \\
\hline $\mathrm{TiO}_{2}$ & 0.34 \\
\hline $\mathrm{CaO}$ & 2.27 \\
\hline $\mathrm{MgO}$ & 1.66 \\
\hline $\mathrm{K}_{2} \mathrm{O}$ & 3.24 \\
\hline $\mathrm{Na}_{2} \mathrm{O}$ & 1.04 \\
\hline
\end{tabular}

The Sakhaptinsk zeolite was characterized by using X-ray diffraction (XRD), thermal (TGA), Fourier transform infrared (FTIR), scanning electron microscope (SEM), and chemical analyses techniques.

XRD analysis of the sample was performed using $\mathrm{CuK}_{\alpha}$-radiation of a DRON-3.0 X-ray diffractometer. TG curve was measured from $20{ }^{\circ} \mathrm{C}$ to $1000{ }^{\circ} \mathrm{C}$ at a rate of $10{ }^{\circ} \mathrm{C}$ $\mathrm{min}^{-1}$ with SDT Q600 apparatus. The water concentration in the sample was determined from the TG curve mass loss.
The determination of specific surface area $\left(S_{\mathrm{sp}}\right)$ was performed by a method of low-temperature nitrogen adsorption (BET) using Sorbi-M device. The infrared spectra of the zeolite rock were obtained using a Fourier transform infrared spectrometer Nicolet 5700. The FTIR spectra in the wave number range from 400 to $4000 \mathrm{~cm}^{-1}$ were obtained by using $\mathrm{KBr}$ pellet technique. SEM images of the zeolite were made by means of a JSM-7500FA scanning electron microscope.

\subsection{Water Treatment Studies}

The zeolite rock was ground in a metal mortar and divided into the fractions by mechanical sieves. The fraction $1.0-2.0 \mathrm{~mm}$ was washed with distilled water to remove turbidity and was dried at room temperature.

The glass column was filled with the zeolite sample of 70 $\mathrm{mL}$. The preliminary activation of the zeolite sample with $10 \%$ $\mathrm{NaCl}$ solution was carried out. Then, the treated sample of zeolite was washed with distilled water. The water was run through the column at filtration velocity of $7 \mathrm{~mL} / \mathrm{min}$. We selected sequentially every $100 \mathrm{~mL}$ of filtered water for analysis. After filtration the ion concentrations in the aqueous phase were measured using spectrophotometer KFK-2. The efficiency of impurities removal was estimated as the difference of pollutant concentrations in aqueous phase between the initial sample and the filtrate divided by the initial concentration of pollutant.

The experiments on the water purification were performed using two samples of the natural water from the village Baturino of Kozhevnikovsky district (Tomsk region, West Siberia, Russia). The chemical composition of the water samples is shown in Table 2. The concentrations of substances in water are expressed in milligrams per liter $(\mathrm{mg} / \mathrm{L})$.

Table 2. Chemical composition of the underground water

\begin{tabular}{|c|c|c|}
\hline \multirow{2}{*}{ Component } & \multicolumn{2}{|c|}{ Number of the Sample } \\
\cline { 2 - 3 } & 1 & 2 \\
\hline $\mathrm{pH}$ & 6.7 & 7.7 \\
\hline $\mathrm{CO}_{2}$ & 105.6 & 48.4 \\
\hline $\mathrm{HCO}_{3}{ }^{-}$ & 439.2 & 335.5 \\
\hline $\mathrm{SO}_{4}^{2-}$ & $<2$ & $<2$ \\
\hline $\mathrm{Cl}^{-}$ & 1.4 & 3.8 \\
\hline $\mathrm{Ca}^{2+}$ & 108.0 & 87 \\
\hline $\mathrm{Mg}^{2+}$ & 13.2 & 10.2 \\
\hline $\mathrm{Na}^{+}$ & 23.5 & 6.1 \\
\hline $\mathrm{K}^{+}$ & 1.9 & 1.12 \\
\hline $\mathrm{Mn}^{2+}$ & 0.2 & 0.14 \\
\hline $\mathrm{Fe}_{\text {total }}$ & 2.3 & 1.5 \\
\hline $\mathrm{TDS}^{*}$ & 589.3 & 443.6 \\
\hline
\end{tabular}

TDS* - the total dissolved solids.

The water sample №1 was taken from a well on the Naberezhnaya Street of the village Baturino; that well for drinking water is not used. The sample №2 was taken from water supply system of Baturino; it is wellbore water, passed the stage of sedimentation. The chemical composition of the samples is shown in the table, according to which the 
wellbore water Kozhevnikovsky district is characterized as calcium bicarbonate, neutral, moderately hard (5.2-6.4 meq/L).

The concentration of iron and manganese in the water samples exceeded MAC in drinking water pursuant to regulations SanPiN 2.1.4.1074-01. Iron content is 7.7 MAC for the water sample №1 and 5 MAC for the water sample №2; Manganese content is 2MAC for the water sample №1 and 1.4MAC for the water sample №2. The water of such quality cannot be used and is required to be treated.

\section{Results and Discussion}

\subsection{Characterization of Zeolite Sample}

The XRD pattern of the Sakhaptinsk zeolite sample is shown in Fig. 1. XRD analysis shows that crystalline phases of the tested sample are clinoptilolite, quartz, feldspar, and cristobalite. The major crystalline phase $(45-50 \%)$ is clinoptilolite. This result is in good agreement with literature data for other deposits of the zeolites $[10,11]$.

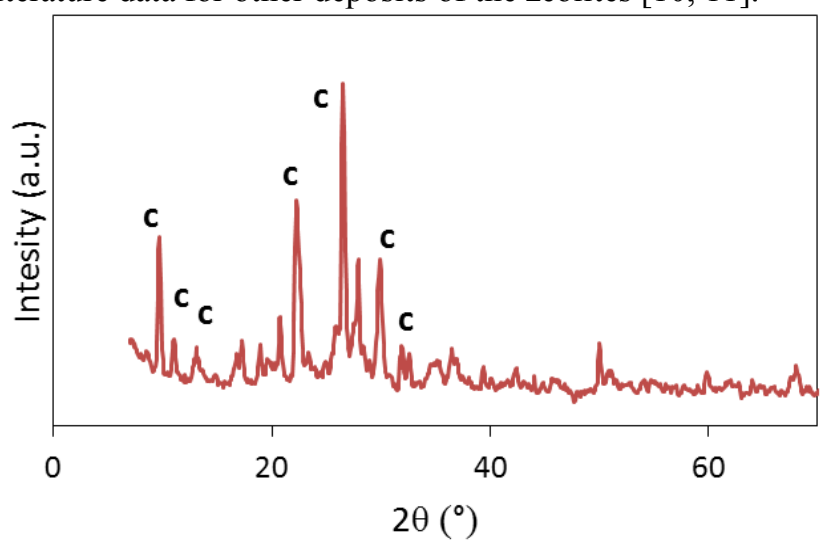

Figure 1. XRD pattern of the Sakhaptinsk zeolite sample: $\mathrm{c}$ clinoptilolite.

Figure 2 illustrates SEM images of the zeolite sample. The stick-shaped particles with size 5-15 $\mu \mathrm{m}$ and plate-shaped particles with size $2-10 \mu \mathrm{m}$ are clearly observed. They aggregated into complex conglomerates (agglomerates).

The BET surface area of the studied zeolite sample was determined $-19.2 \mathrm{~m}^{2} / \mathrm{g}$.

Thermal behavior of the zeolite was investigated by means of TG analysis. TG curve of the zeolite sample is shown in Fig. 2. The DTA curve of the sample displays a single endothermic effect in the temperature range from $59{ }^{\circ} \mathrm{C}$ to $145^{\circ} \mathrm{C}$ with a maximum of $77.9^{\circ} \mathrm{C}$ as a result of a single-step dehydration process. The total weight loss for the sample determined by TG analysis is $9.22 \%$. Water loss continued smoothly from $20{ }^{\circ} \mathrm{C}$ to $700{ }^{\circ} \mathrm{C}$. Such form of the curve is typical for the cliniptilolite. Most of the physically adsorbed water is lost between $20{ }^{\circ} \mathrm{C}$ and $300{ }^{\circ} \mathrm{C}$ and in the broad interval between $300{ }^{\circ} \mathrm{C}$ and $600{ }^{\circ} \mathrm{C}$ more strongly associated water is lost.

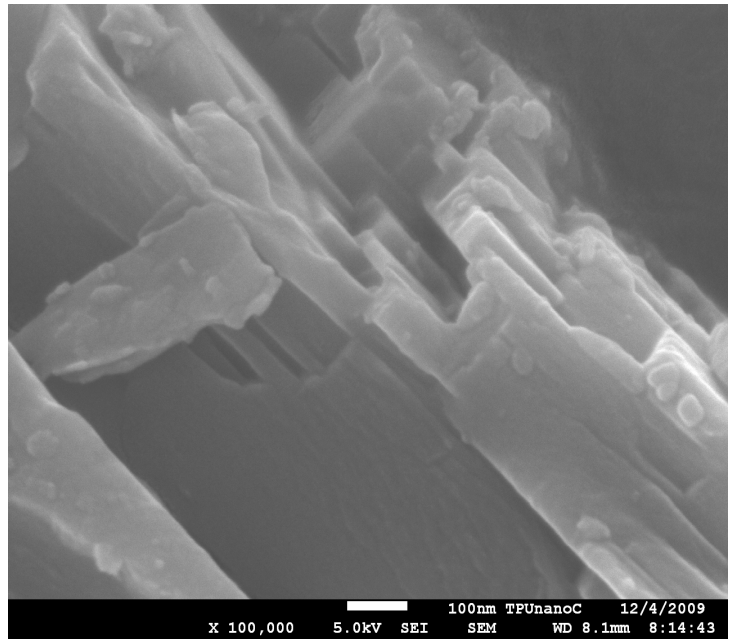

A

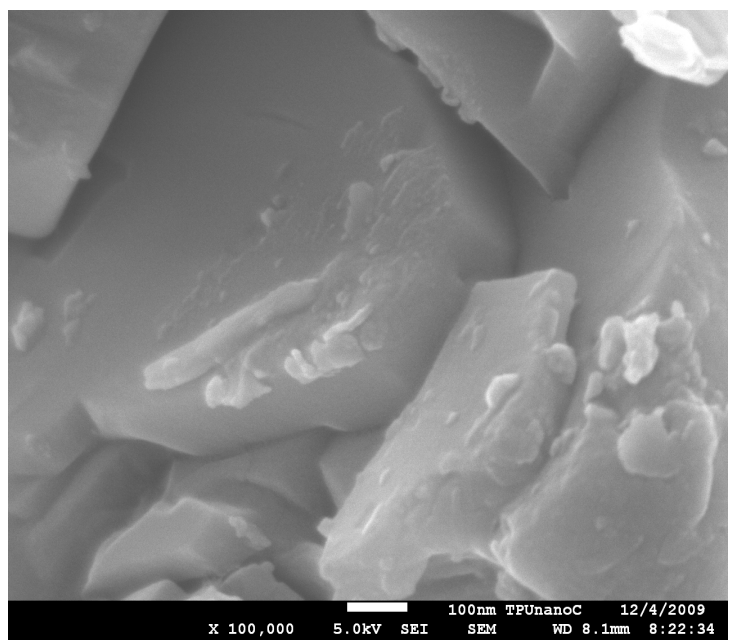

B

Figure 2. SEM images of the Sakhaptinsk zeolite: stick-shaped particles (A); plate-shaped particles (B).

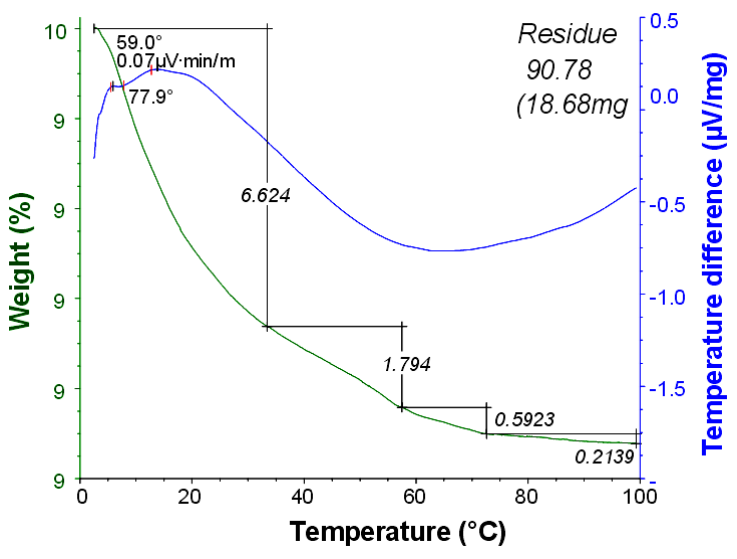

Figure 3. TG-DTA curves of the zeolite sample.

The results on the FTIR study are shown in Fig. 4. FTIR spectra were recorded for the raw zeolite rock (1) and for the zeolite sample after the experiment on the ground water treatment (2). 


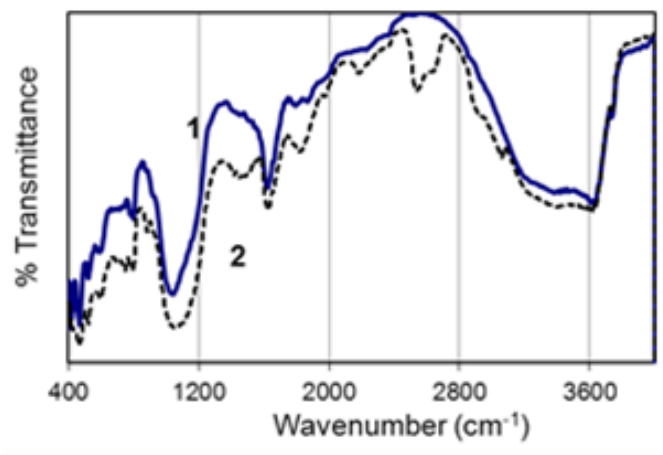

Figure 4. FTIR spectra of the zeolite sample before water treatment (1) and after filtration of underground water (2).

The most intensive absorption band is observed at $1040 \mathrm{~cm}^{-1}$ and corresponds to the asymmetric stretching vibrations of $\mathrm{Si}-\mathrm{O}-\mathrm{Si}$ [10]. The absorption bands of 804 and $780 \mathrm{~cm}^{-1}$ are associated with the stretching vibrations of $v(\mathrm{Al}-\mathrm{O})$, and $473 \mathrm{~cm}^{-1}$ - with the bending vibrations of $\delta\left(\mathrm{Al}-\mathrm{O}_{4}\right)$. The vibration band with peaks of $1625 \mathrm{~cm}^{-1}$ is assigned to the bending vibration of sorbed water. The strong wide band in the range $3253-3734 \mathrm{~cm}^{-1}$ are associated with the presence of zeolite water: $3637.5 \mathrm{~cm}^{-1}$ the absorption band $v(\mathrm{OH})$ of hydrogen bonds of $\mathrm{OH}$ groups; $3618.2,3398.4,3233.8 \mathrm{~cm}^{-1}$ - bands of asymmetric and symmetric stretching vibrations of isolated $\mathrm{OH}$ groups.

The sample after the water filtration (Fig. 4-2) shows the additional bands at $747,885,1446,1822$, and $2535 \mathrm{~cm}^{-1}$. These peaks are attributable to the vibration of carbon-oxygen double bond in the carbonate ion [22].

\subsection{Results of Water Treatment}

The results of experiments on the purification of well water after filtration through Sakhaptinsk zeolite are shown in Fig. 5, 6 and 7.

It can be observed from Fig. 5 that $\mathrm{Fe}_{\text {total }}$ removal efficiency in the experiments was $96 \%$ after passing through the column $700 \mathrm{~mL}$ of the water sample №1, Table 2 (underground water from the well), and $100 \%$ after passing through column $500 \mathrm{~mL}$ of the water sample №2 (water from drinking supply system).

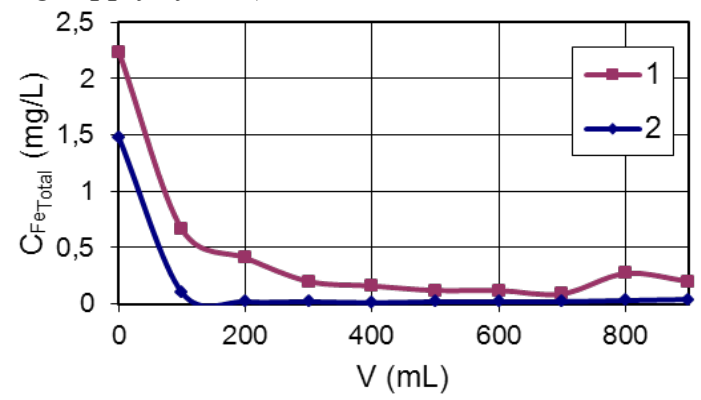

Figure 5. Changes in $\mathrm{Fe}_{\text {total }}$ concentration in the filtrate: 1 - water sample № $1 ; 2$ - water sample № 2 .

Removal efficiency of $\mathrm{Mn}^{2+}$ was determined for the water sample №2, and it was $93 \%$ after passing through the filter $1000 \mathrm{~mL}$ of water (Fig. 6).

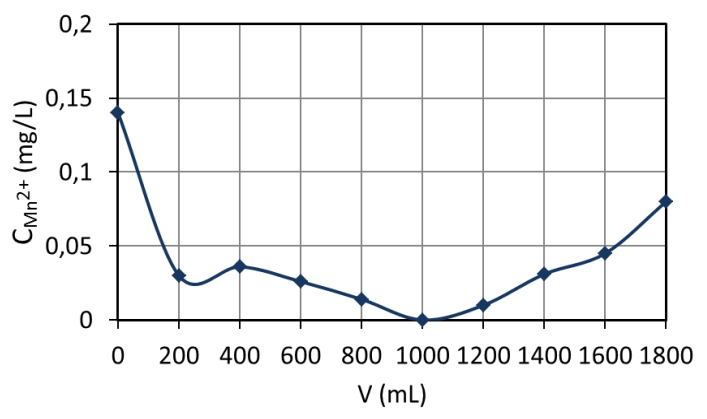

Figure 6. Changes in $\mathrm{Mn}^{2+}{ }_{1}$ concentration in the filtrate.

The obtained results show that the natural zeolite of Sakhaptinsk deposit can be used for removal of iron and manganese from underground water. High initial concentration of iron and manganese reduced by filtering water through zeolite to the limit values according to the regulations SanPiN 2.1.4.1074-01: $0.3 \mathrm{mg} / \mathrm{L}$ for iron and $0.1 \mathrm{mg} / \mathrm{L}$ for manganese.

In addition to the iron removal, zeolites can be simultaneously used for water softening, the removal of hardness, in particular, the $\mathrm{Ca}^{2+}$ ion removal Therefore it was of interest to test the effectiveness of Sakhaptinsk zeolite towards $\mathrm{Ca}^{2+}$ ions. For the water sample №2 $\mathrm{Ca}^{2+}$ removal efficiency was $100 \%$ after passaging through the column of 200-500 mL of water (Fig. 7), and for the water sample 1, in which initial concentration of $\mathrm{Ca}^{2+}$ was higher, efficiency was $63 \%$.

In the process of softening $\mathrm{Ca}$ ions are removed from the water and replaced by ions of $\mathrm{Na}$. As a result, hardness salts are removed from the water, and the sodium salts appeared in the filtrate. In the FTIR spectrum of the zeolite sample after filtration of underground water (Fig. 4-2) there are additional absorption bands 747, 885, 1446, 1822, and 2535 $\mathrm{cm}^{-1}$, which are assigned to calcium carbonate.

The main exchangeable ion during the process of water treatment on the zeolite is sodium ion. Fig. 7 presents an increase in concentration of $\mathrm{Na}^{+}$ion during ion-exchange during filtration of water through the column filled with zeolite, while the concentration of $\mathrm{K}^{+}$and $\mathrm{Ca}^{2+}$ ions in the filtrate decreases.

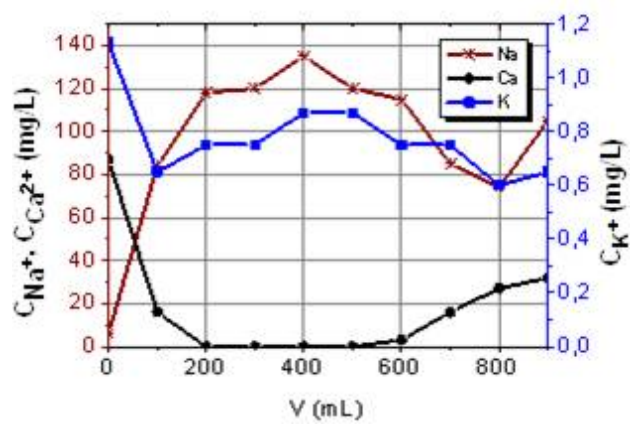

Figure 7. Changes in $\mathrm{Na}^{+}, \mathrm{Ca}^{2+}$ and $\mathrm{K}^{+}$concentrations in the filtrate.

Pre-treatment of the zeolite by the $\mathrm{NaCl}$ solution before 
the experiments in water purification contributed to the saturation of the zeolite with exchangeable sodium ions, thus the zeolite was transferred to the Na-form. It is a cheap and inexpensive method of zeolite preparation and regeneration, in the process of which the exchange effectiveness can be increased significantly.

The efficiency of impurities removal in the water treatment process on the zeolites depends on the fraction size [23]. Total surface the active sites of the zeolite increases with decreasing particle size, as well as the number of direct contacts of impurity ions with the main channels. In this connection the sorption properties of zeolite increases with decreasing particle size. On the other hand, earlier we had carried out experiments showing that the use of fine fraction $\leq 1.0 \mathrm{~mm}$ of Sakhaptinsk zeolite for water treatment under dynamic conditions is inexpedient due to the separation problems of the fine dispersed phase from the aqueous medium, which is difficult to perform by conventional methods. Despite the absence of toxicity of the zeolite to humans [24], we propose to use the zeolite fraction $1.0-2.0 \mathrm{~mm}$ for improving the quality of drinking water, which is more resistant to mechanical abrasion under dynamic conditions. All experiments presented in this work were performed on the fraction size of 1.0-2.0 mm.

\section{Conclusion}

In this study, characterization of the natural zeolite from Sakhaptinsk deposit (Krasnoyarsk Territory, Russia) was made and the efficiency of those in the removal of iron, manganese, calcium from underground water has been investigated. The following methods of analysis were used: $\mathrm{X}$-ray diffraction analysis, thermal analysis, Fourier infrared spectroscopy, electron-microscopic analysis, chemical analysis. It was found that main phase of zeolitic tuff is clinoptilolite.

The obtained results indicate high efficiency of underground water purification (Kozhevnikovsky district, Tomsk region, Russia) by passing it through the filter with zeolite loading. The achieved removal efficiency in the experiments was for $\mathrm{Fe}_{\text {total }} 96-100 \%$, for $\mathrm{Mn}^{2+} 93 \%$, and for $\mathrm{Ca}^{2+} 63-100 \%$, depending on the initial concentration. The concentration of these substances in the filtrate after treatment does not exceed the maximum allowable concentration in drinking water according to the regulations SanPiN 2.1.4.1074-01 and suitable for drinking and domestic purposes of the population.

\section{Acknowledgements}

This research was supported by the Federal Programs GK of Russian Federation № 16.552.11.7063 and № 14.518.11.7017.

\section{REFERENCES}

[1] L. I. Dubrovskaya, V. A. Zemtsov, V. A. Lgotin. Some Problems of Ground Water Near Tomsk, West Siberia, Russia, in: Groundwater in the Urban Environment: Selected City Profiles, J. Chilton (ed.), Rotterdarm, 119-122, 1999.

[2] L. V. Serikov, E. A. Tropina, L. N. Shiyan, F. H. Frimmel, G. Metreveli, M. Delay. Iron oxidation in different types of groundwater of Western Siberia, Journal of Soils and Sediments, Vol.9, No.2, 103-110, 2009.

[3] B. G. Shubin, N. A. Yavorovsky, L. V. Serikov, L. N. Shiean, E. A. Tropina, Technological peculiarities of drinking water preparation from underground sources, in: Proceedings of the 7th Korea-Russia International Symposium on Science and Technology, Ulsan, Korea, 164-168, 2003.

[4] C. Gottschalk, J. A. Libra, A. Saupe. Ozonation of Drinking Water and of Wastewater: A practical Guide to Understanding Ozone and its Application. Wiley, Weinheim, 2010.

[5] J.-W. Kang, H.-S. Park, R.-Y. Wang, M. Koga, K. Kadokami, H.-Y. Kim, E.-T. Lee, S.-M. Oh. Effect of Ozonation for Treatment of Micropollutants Present in Drinking Water Source, Water Science and Technology, Vol.36, No.12, 299-307, 1997.

[6] J. P. Duguet, A. Bruchet, J. Mallevialle. New Advances in Oxidation Processes: the Use of Ozone/hydrogen Peroxide Combination for Micropollutant Removal in Drinking Water, Water Supply, Vol.7, No.4, 115-124, 1989.

[7] V. L. Serikow, L. N. Shijan, E.A. Tropina. Oxidation of Different Forms of Iron Compositions in the Underground Water, in: Proceedings of the 8th Korea-Russia International Symposium on Science and Technology, Tomsk, Russia, Vol.2, pp. 82-84, 2004.

[8] N. A. Yavorovsky, S. S. Peltsman, J. I. Kornev, Yu, V. Volkov. Technology of Water Treatment Using Pulsed Electric Discharges, in: Proceedings of the 4th Korea-Russia International Symposium on Science and Technology, Ulsan, Korea, Vol.3, 422-427, 2000.

[9] M. A. Malik, A. Ghaffar, S. A. Malik. Water purification by electrical discharges, Plasma Sources Sci. Technol., Vol.10, No.1, 82-91, 2001.

[10] D. W. Breck. Zeolite Molecular Sieves^ structure, chemistry, and use. John Wiley \& Sons, New York, 1974.

[11] C. Murphy, O. Hrycyk, W. Gleason. Natural Zeolites: Occurence, Properties, Use. Pergamon, Oxford, 1978.

[12] S. Wang, Y. Peng. Natural zeolites as effective adsorbents in water and wastewater treatment, Chemical Engineering Journal, Vol.156, No. 1, 11-24, 2010.

[13] E. Erdem, N. Karapinar, R. Donat. The removal of heavy metal cations by natural zeolites, Journal Colloid and Interface Science, Vol.280, 300-314, 2004.

[14] K. Saltali, A. Sari, M. Aydin. Removal of ammonium ion from aqueous solution by natural Turkish (Yildizeli) zeolite for environmental quality, Journal of Hazardous Materials, Vol.141, 258-263, 2007.

[15] Y. F. Wang, F. Lin, W. Q. Pang. Ammonium exchange in aqueous solution using Chinese natural clinoptilolite and 
modified zeolite, Journal of Hazardous Materials, Vol.142, 160-164, 2007.

[16] D. Barlokova, J. Ilavsky. Removal of Iron and Manganese from Water Using Filtration by Natural Materials, Polish Journal of Environmental Studies, Vol.19, No.6, 1117-1122, 2010

[17] A. M. Anielak, M. Arendacz. Iron and Manganese Removal Effects Using Zeolites, Ochrona Srodowiska, Vol.9, 9-18, 2007.

[18] M. K. Doula. Removal of Mn2+ ions from drinking water by using clinoptilolite and a clinoptilolite-Fe oxide system, Water Research, Vol.40, 3167-3176, 2006.

[19] V. N. Gerasimova. Natural zeolites as petroleum product adsorbents, Chemistry for Sustainable Development, Vol.11, 471-478, 2003.

[20] E. E. Sirotkina, L. Yu. Novoselova. Materials for adsorption purification of water from petroleum and oil products,
Chemistry for Sustainable Development, Vol.13, 359-375, 2005.

[21] V. N. Smirenskaya, V. I. Vereshchagin. Prospects of using zeolite rocks of Siberia in silicate materials, Glass and Ceramics, Vol.59, No.11-12, 414-419, 2002.

[22] W. B. White. The carbonate minerals, in: The infrared Spectra of Minerals, V. C. Farmer (ed.), Mineralogical Society, London, 227-284, 1974.

[23] M. Sprynskyy, M. Lebedynets, A. P. Terzyk, P. Kowalczyk, J. Namiesnik, B. Buszewski. Ammonium sorption from aqueous solutions by the natural zeolite Transcarpathian clinoptilolite studied under dynamic conditions, Journal of Colloid and Interface Science, Vol.284, 408-415, 2005.

[24] Human \& Environmental Risk Assessment on ingredients of household cleaning products: Zeolites A, P and X. CAS No. 1344-00-9 (Sodium Aluminium Silicate) CAS No.1318-02-1 (Zeolites), Edition 1.0 September 2005, Online available from http://www.heraproject.com 